\title{
Avaliação do Crescimento de Tecidos e Órgãos de Novilhos Mestiços Holandês-Gir Durante o Ganho Compensatório. 1. Carcaça ${ }^{1}$
}

\section{Maria Izabel Vieira de Almeida ${ }^{2}$, Carlos Augusto de Alencar Fontes ${ }^{3}$, Fernando Queiroz de Almeida $^{4}$, Sebastião de Campos Valadares Filho ${ }^{2}$, Rodrigo Furtado Guimarães ${ }^{2}$}

\begin{abstract}
RESUMO - O objetivo deste trabalho foi analisar os efeitos da restrição alimentar anterior ao confinamento sobre o crescimento e a composição química da carcaça e seus componentes em bovinos. Foram utilizados vinte e quatro novilhos mestiços Holandês-Gir com idade de 19,3 $\pm 5,1$ meses e peso vivo de 202,1 $\pm 49,1 \mathrm{~kg}$, ao início do experimento. Quinze animais foram confinados após um período de restrição de pasto (grupo ganho compensatório), enquanto nove deles tiveram livre acesso ao pasto (grupo ganho contínuo). Foram abatidos três animais de cada grupo, no início, aos 28 e aos 112 dias do confinamento e, aos 56 e 84 dias de confinamento, foram abatidos três animais do grupo de ganho compensatório. Durante o confinamento, os animais do grupo de ganho compensatório e do grupo de ganho contínuo receberam alimentação ad libitum, composta por silagem de milho e $26 \%$ de concentrado, na matéria seca. As taxas de crescimento relativo foram avaliadas por meio de equações alométricas. As taxas de deposição de proteína, gordura e energia na carcaça, em relação ao ganho de peso de corpo vazio, não diferiram entre os tratamentos. A deposição de proteína na carcaça, em relação ao ganho de peso vivo, foi maior nos animais em ganho compensatório que nos de ganho contínuo. O ganho de peso compensatório causou redução na deposição de proteína no tecido adiposo e aumento na deposição de gordura nos ossos da carcaça.
\end{abstract}

Palavras-chave: bovino, crescimento, carcaça, equações alométricas

\section{Evaluation of Growth of Tissues and Organs of Crossbreed Holstein-Gyr Steers During Compensatory Growth. 1. Carcass}

\begin{abstract}
The research aimed to analyze the effects of feed restriction prior to confinement on growth and chemical composition of the carcass and carcass components in cattle. Twenty-four Holstein-Gyr crossbred steers, with 19,3 $\pm 5,1$ months of age and 202,1 $\pm 49,1 \mathrm{~kg} \mathrm{LW}$, at the beginning of the trial were used. Fifteen animals were confined after a 104-day period of forage restriction, in which it was intended to keep body weight unchanged (compensatory gain group), while nine of them had free access to pasture (continuous gain group). At beginning of the experiment and at days 28 and 112 of confinement, three animals of each group were slaughtered, and at days 56 and 84, three animals of compensatory gain group were slaughtered. During confinement, the animals from the compensatory gain group and continuous gain group were fed ad libitum; composed by corn silage and $26 \%$ of concentrate, as dry matter basis. The relative growth rates were evaluated through allometric equations. The rates of protein, fat and energy deposition in the carcass did not differ between treatments, in relation to empty-body weight gain. The protein deposition, in relation to empty body gain, was greater in compensatory growth group than in the continuous gain group. The compensatory weight gain cause a reduction in the protein deposition rate in carcass adipose tissue and an increase in the fat deposition rate in the bones of the carcass.
\end{abstract}

Key Words: allometric equations, carcas, cattle, growth

\section{Introdução}

Na pecuária de corte, busca-se aumentar a deposição de proteína no tecido muscular esquelético, mantendo o conteúdo de gordura dos animais dentro do mínimo necessário, visando um produto de melhor qualidade para o consumidor e, ao mesmo tempo, melhorar a eficiência econômica para o produtor. Para atingir esses objetivos, devem-se conhecer os processos de crescimento e desenvolvimento dos animais (GRANT e HELFERICH, 1991).

O crescimento dos componentes corporais do animal, em relação ao todo, segue o padrão de crescimento alométrico. A curva típica de crescimento, durante a vida, apresenta forma sigmóide, ou seja, o crescimento durante a primeira etapa da vida é lento, seguido de um período de auto-aceleração, até atingir o ponto máximo da taxa de crescimento, por volta da puberdade, seguida de uma fase de auto-desaceleração (BERG e BUTTERFIELD, 1976). As curvas de

\footnotetext{
1 Parte da tese apresentada à Universidade Federal de Viçosa para obtenção do título de Doctor Scientiae.

2 UFV/DZO - 36571-000 - Viçosa, MG. E.mail: miva@homenet.com.br

3 UENF/CCTA - 28015-820 - Campos, RJ. E.mail: caafontes@uenf.br

4 UFRRJ/DMCV-IV - 23851-970 - Seropédica, RJ. E.mail: falmeida@ufrrj.br
} 
crescimento dos componentes mais importantes da carcaça, ou seja, músculo, osso e gordura de animais em fase de engorda, evidenciam que os tecidos muscular e ósseo crescem em velocidade proporcionalmente menor que a carcaça, enquanto o tecido adiposo apresenta comportamento inverso. Conseqüentemente, o teor de gordura da carcaça aumenta com a maturidade do animal. Essas curvas de crescimento variam entre indivíduos; em animais de grande porte, ou seja, de maior peso à maturidade, a fase de acúmulo rápido de gordura ocorre a um peso mais elevado. Comparando animais de portes diferentes a um mesmo peso, o de maior porte não será tão maduro como o de menor tamanho e terá menor acúmulo de gordura.

A composição da carcaça é fator relevante na determinação do valor comercial dos bovinos de corte, ocorrendo, à medida que o animal cresce, mudanças nas proporções relativas dos tecidos ósseo, muscular e adiposo. Para se estabelecer a época ideal de abate, é importante que se conheçam as variações no crescimento relativo e no conteúdo de proteína e gordura dos principais componentes corporais. Além disso, é muito importante identificar o padrão do ganho de peso diário de carcaça, músculos, gordura e ossos, em relação à taxa de crescimento corporal, durante o período de confinamento(FRANCI et al., 1996).

O plano de alimentação e o peso de abate geralmente são variáveis consideradas pelos produtores e abatedouros como indicativos das condições do produto final, mas o conhecimento do desenvolvimento corporal, que depende da taxa de crescimento, determinada pelo nível de alimentação, também deve ser levado em consideração (GIORGETTI et al., 1996). Os trabalhos realizados com novilhos oriundos de rebanhos de dupla finalidade, no Brasil, têm enfatizado avaliações da composição corporal do ponto de vista comercial, detendo-se no estudo de animais terminados em confinamento, sem considerar as suas condições anteriores.

Os trabalhos que envolvem crescimento alométrico de componentes corporais em bovinos de leite ou de corte indicam que o padrão de desenvolvimento é influenciado pelo plano de alimentação, pela raça, pelo sexo e pela duração do período avaliado. Os resultados obtidos com animais de raças de origem européias não são necessariamente aplicáveis a animais zebuínos ou oriundos de cruzamentos entre raças européia e zebuínas, assim como não se pode extrapolar resultados obtidos em uma condição espe- cífica de produção para condições diferentes (SEEBECK, 1968).

OLTJEN et al. (1986) desenvolveram um modelo mecanístico para predição da deposição de proteína a partir do conteúdo inicial e final de DNA, que admite que a diferença entre o excesso de energia líquida requerida para síntese protéica e aquela disponível para ganho é depositada sob a forma de gordura e que também utiliza a relação entre o peso atual do animal e o peso adulto para ajustar diferenças de peso adulto e aquelas ocasionadas pelo uso de implantes (NATIONAL RESEARCH COUNCIL - NRC, 1996). O sistema adotado pelo INSTITUT NATIONAL DE LA RECHERCHE AGRONOMIQUE - INRA (1989) utiliza relações alométricas entre o peso corporal vazio e o peso vivo e o peso dos componentes químicos e o peso da massa corporal desengordurada para predizer os requerimentos de energia e proteína. Os coeficientes das equações são os parâmetros da equação de Gompertz, os quais representam alterações do peso vivo com o tempo. O sistema admite que a quantidade de lipídeos depositada diariamente é proporcional ao ganho de peso vivo diário elevado à potência 1,8 ; enquanto o ganho diário de proteína é calculado a partir da massa corporal desengordurada, tendo em vista que o conteúdo de proteína do ganho de peso desengordurado é pouco influenciado pelo tipo de animal, pela taxa de crescimento ou pelo nível de alimentação.

Os objetivos deste trabalho foram avaliar a influência do ganho de peso compensatório sobre o crescimento alométrico e o acúmulo de gordura, proteína e energia na carcaça de novilhos mestiços HolandêsGir castrados e obter equações de predição da deposição de gordura, proteína e energia na carcaça, com o aumento de peso do animal.

\section{Material e métodos}

Foram utilizados 24 novilhos mestiços HolandêsGir com idade de 19,3 $\pm 5,1$ meses e peso vivo de $202,1 \pm 49,1 \mathrm{~kg}$, ao início do experimento. Quinze animais foram confinados após um período de restrição de pasto (grupo ganho compensatório), enquanto nove deles tiveram livre acesso ao pasto (grupo ganho contínuo). Foram abatidos três animais de cada grupo, no início, aos 28 e aos 112 dias do confinamento e, aos 56 e 84 dias de confinamento, foram abatidos três animais do grupo de ganho compensatório. O período de confinamento teve duração total de 112 dias. 
528 Rev. bras. zootec.

Durante o confinamento, os animais receberam dieta única, constituída de silagem de milho e concentrado à base de farelo de soja, fubá de milho, uréia, fosfato bicálcico, calcário, sal e mistura mineral. A ração continha $26 \%$ de concentrado na matéria seca e foi calculada de acordo com as normas do AFRC (1993), de modo a permitir ganho de peso vivo diário de $1,2 \mathrm{~kg}$, para os animais alimentados ad libitum, atendendo ao mesmo tempo às exigências de proteína degradável no rúmen. A energia metabolizável (EM) foi estimada a partir do valor de energia digestível (ED) da ração obtida em dois ensaios de digestibilidade, multiplicado pelo fator 0,82 . A composição da dieta, os coeficientes de digestibilidade aparente dos nutrientes e os conteúdos de MS, MO, FDN, EE e EB na dieta e nas fezes foram descritos por ALMEIDA et al. (2001).

Os animais foram abatidos nos tempos pré-determinados e após os abates foram pesados e coletadas amostras dos seguintes componentes: sangue, cabeça, pés, couro, cauda, rúmen-retículo, omaso, abomaso, intestinos delgado e grosso, mesentério, gordura interna, baço, coração, fígado, pulmões, rins, língua e carne industrial e, em conjunto, esôfago, traquéia, aparelho reprodutor e gordura. De um animal de cada tratamento, foram pesadas, dissecadas e retiradas amostras da cabeça e de um pé dianteiro e um traseiro. As amostras foram moídas ou picadas e armazenadas em freezer, para posteriores análises. As carcaças foram serradas ao meio, e as duas meiacarcaças pesadas individualmente e mantidas em câmara fria, à temperatura de $-5^{\circ} \mathrm{C}$, durante aproximadamente 18 horas; em seguida, foi retirada da meia-carcaça direita uma secção transversal da $9 \underline{a}$ à 11 a costela (secção HH) (HANKINS e HOWE, 1946), que foi dissecada, e as porções de músculos, ossos e tecido adiposo foram pesadas e armazenadas em freezer, para posteriores análises.

As amostras de rúmen-retículo, omaso, abomaso, intestinos delgado e grosso, gordura interna e mesentério foram agrupadas proporcionalmente ao peso de cada porção, formando uma amostra composta, representando o trato gastrintestinal mais gordura visceral (TGI + gordura visceral), enquanto as amostras de rúmen-retículo, omaso, abomaso e intestinos delgado e grosso foram agrupadas, formando uma amostra composta, representando as vísceras do TGI. Do mesmo modo, as amostras de fígado, coração, pulmão, rins, baço, língua, carne industrial, esôfago-traquéia e aparelho reprodutor formaram uma amostra composta de órgãos para cada animal. As amostras foram pré-desengorduradas conforme descrito por KOCK e PRESTON (1979), moídas em moinho de bola e submetidas às determinações de nitrogênio total e extrato etéreo.

Os conteúdos corporais de energia, proteína, gordura e água foram determinados de acordo com sua concentração porcentual nas amostras de vísceras, órgãos, couro, sangue, cauda, cabeça, pés, músculos, tecido adiposo e ossos, multiplicadas pelo peso de cada componente.

Para descrever o acúmulo de proteína, gordura e energia na carcaça e em seus componentes (músculo, tecido adiposo e ossos), utilizou-se o modelo alométrico, ajustando-se equações de regressão do logaritmo do conteúdo de proteína e gordura, em kg, e de energia, em Mcal, em função do logaritmo do conteúdo de proteína, gordura e energia do corpo vazio, conforme o modelo:

$$
\mathrm{Y}_{\mathrm{ij}}=\mu+\mathrm{b}_{\mathrm{i}} \mathrm{X}_{\mathrm{j}}+\mathrm{e}_{\mathrm{ij}}
$$

em que $Y_{\mathrm{ij}}$ é logaritmo do conteúdo de proteína $(\mathrm{kg})$, gordura (kg) e energia (Mcal) na carcaça e em seus componentes do animal $j$ do tratamento $i ; \mu$, efeito da média ( intercepto); $b_{i}$, coeficiente de regressão do logaritmo do conteúdo de proteína $(\mathrm{kg})$, gordura $(\mathrm{kg})$ e energia (Mcal) na carcaça e em seus componentes, em função do logaritmo do conteúdo de proteína, gordura (kg) e energia (Mcal) do corpo vazio, dos animais do tratamento $i$, em que $i=1$, ganho contínuo, e 2, ganho compensatório; $X_{\mathrm{ij}}$, logaritmo do conteúdo de proteína $(\mathrm{kg})$, gordura $(\mathrm{kg})$ e energia (Mcal) do corpo vazio, do animal j do tratamento $\mathrm{i}$; e $\mathrm{e}_{\mathrm{ij}}$, erro aleatório, pressuposto normalmente distribuído, com média zero e variância $\sigma^{2}$.

Por derivação dessas equações de regressão, obtiveram-se equações de predição do aumento do conteúdo de proteína $(\mathrm{kg})$, gordura, $(\mathrm{kg})$ e energia (Mcal) na carcaça e em seus componentes, por quilograma de proteína e gordura ou megacaloria de energia ganho no corpo vazio (GPCVZ), do tipo:

$$
\mathrm{Y}^{\prime}=\mathrm{b} * 10^{\mathrm{a}} * \mathrm{X}^{\mathrm{b}-1}
$$

em que Y' é aumento no conteúdo de proteína $(\mathrm{kg})$, gordura (kg) ou energia (Mcal) na carcaça e em seus componentes, por $\mathrm{kg}$ de proteína e gordura ou por Mcal de energia ganho no GPCVZ; a e b, intercepto e coeficiente de regressão, respectivamente, das equações de regressão do conteúdo de proteína $(\mathrm{kg})$, gordura (kg) ou energia (Mcal) na carcaça e em seus componentes; e X, kg de proteína e gordura ou Mcal de energia no PCVZ.

A precocidade das mudanças nas composições da carcaça e de seus componentes, durante o período experimental, foi analisada em função do valor do 
coeficiente b. Aplicou-se o teste de identidade de modelos (GRAYBILL, 1976) às equações obtidas e, nos casos em que o teste indicou a ausência de diferenças entre as equações referentes aos dois tratamentos, foram ajustadas equações conjuntas para os mesmos. Quando apropriado, foram aplicados testes de identidade de interceptos (NETER e WASSERMAN, 1974). No ajustamento das equações de regressão e nas análises de variância, foi utilizado o programa LSMLMW, versão PC-1 (HARVEY, 1987).

\section{Resultados e Discussão}

As equações de regressão dos logaritmos dos conteúdos de proteína na carcaça e em seus componentes, em relação aos logaritmos dos conteúdos de proteína no corpo vazio, ao longo do período de confinamento, descrevendo a velocidade relativa de sua deposição, para animais que experimentaram ganho de peso contínuo ou compensatório, estão relacionadas na Tabela 1 .

Os estudos de crescimento alométrico examinam o crescimento relativo de um componente corporal em relação a um conjunto de componentes ou ao corpo, identificando sua taxa de desenvolvimento
(SEEBECK, 1968). Conforme já referido, equações diferentes para os tratamentos ganho contínuo e ganho compensatório somente são apresentadas nas situações em que os testes de identidade de modelo ou de interceptos indicaram haver diferença entre tratamentos. Valores do coeficiente $\mathrm{b}$ iguais a 1 indicam que a velocidade de crescimento do componente avaliado no tecido ou órgão (parte) é semelhante ao crescimento verificado no todo (PCVZ). Valores menores que 1 indicam que o componente está crescendo, na parte, em taxa mais lenta do que no todo, e valores maiores que 1 indicam que a taxa de crescimento do componente é mais rápida na parte que no todo. Animais em ganho compensatório tendem a apresentar mudanças nos valores de b, em relação a animais que não sofreram restrição alimentar.

Por derivação das equações alométricas, foram obtidas equações de predição que permitem estimar o ganho de proteína na carcaça e em seus componentes, por unidade de acréscimo destes no corpo vazio. Os aumentos de proteína na carcaça e em seus componentes foram estimados por meio das equações de predição e estão relacionados na Tabela 2.

A deposição de proteína na carcaça ocorreu em velocidade próxima ao seu aumento no PCVZ $(\mathrm{b}=1,00610593)$ e foi maior no tecido muscular

Tabela 1 - Equações alométricas relacionando os conteúdos de proteína na carcaça e em seus componentes com o conteúdo no PCVZ e equações de predição do ganho de proteína na carcaça e em seus componentes, em função do ganho de $1 \mathrm{~kg}$ de proteína no corpo vazio (PrPCVZ), em novilhos mestiços em ganho contínuo (GCont) e, ou, ganho compensatório (GComp)

Table 1 - Allometric equations expressing the relation of protein content in carcass and its components with protein content in empty-body weight (EBW) and prediction equations gain of protein in carcass and its components, per $\mathrm{kg}$ of gain of protein in EBW (PrEBW) in crossbred steers, under continuous growth (GCont), and, or, compensatory growth (Gcomp)

\begin{tabular}{|c|c|c|c|}
\hline $\begin{array}{l}\text { Componente } \\
\text { Component }\end{array}$ & $\begin{array}{l}\text { Equações alométricas } \\
\text { Allometric equations }\end{array}$ & $\begin{array}{l}\text { Equações de predição } \\
\text { Prediction equations }\end{array}$ & $\mathrm{R}^{2}$ \\
\hline \multicolumn{4}{|c|}{$\begin{array}{c}\text { Protein } \\
\text { Proína }(\mathrm{kg}) \text { - }\end{array}$} \\
\hline \multicolumn{4}{|l|}{$\begin{array}{l}\text { Carcaça } \\
\text { Carcass }\end{array}$} \\
\hline $\begin{array}{l}\text { GCont } \\
\text { Gcomp } \\
\text { Músculo } \\
\text { Muscle }\end{array}$ & $\begin{array}{l}\hat{Y}=0,54953146 \times \operatorname{PrPCVZ}^{1,00610593} \\
\hat{\mathrm{Y}}=0,56988230 \times \operatorname{PrPCVZ}^{1,00610593}\end{array}$ & $\begin{array}{l}\hat{Y}=0,55288686 \times \operatorname{PrPCVZ}^{0,006106} \\
\hat{\mathrm{Y}}=0,57336196 \times \operatorname{PrPCVZ}^{0,006106}\end{array}$ & 0,99 \\
\hline $\begin{array}{l}\text { GCont e GComp } \\
\text { Tecido adiposo } \\
\text { Adipose tissue }\end{array}$ & $\hat{\mathrm{Y}}=0,201370188 \times \operatorname{PrPCVZ}^{1,16656751}$ & $\hat{Y}=0,23491192 \times \operatorname{PrPCVZ}^{0,166568}$ & 0,96 \\
\hline $\begin{array}{l}\text { GCont } \\
\text { Gcomp } \\
\text { Osso } \\
\text { Bone }\end{array}$ & $\begin{array}{l}\hat{Y}=0,01551753 \times \operatorname{PrPCVZ}^{1,28884807} \\
\hat{\mathrm{Y}}=9,296781654 \times \operatorname{PrPCVZ}^{-0,3627899}\end{array}$ & $\begin{array}{l}\hat{Y}=0,01999974 \times \operatorname{PrPCVZ}^{0,288848} \\
\hat{Y}=-3,37277849 \times \operatorname{PrPCVZ}^{-1,36279}\end{array}$ & 0,55 \\
\hline $\begin{array}{l}\text { GCont } \\
\text { Gcomp }\end{array}$ & $\begin{array}{l}\hat{Y}=0,199762081 \times \operatorname{PrPCVZ}^{0,8790193} \\
\hat{\mathrm{Y}}=0,232471305 \times \operatorname{PrPCVZ}^{0,8790193}\end{array}$ & $\begin{array}{l}\hat{Y}=0,17559472 \times \operatorname{PrPCVZ}^{-0,120981} \\
\hat{\mathrm{Y}}=0,20434676 \times \operatorname{PrPCVZ}^{-0,120981}\end{array}$ & 0,85 \\
\hline
\end{tabular}


530 Rev. bras. zootec.

Tabela 2 - Aumento diário estimado de proteína na carcaça e em seus componentes $(\mathrm{kg})$ em novilhos mestiços em ganho contínuo (GCont) e, ou, ganho compensatório (GComp), por kg de ganho de proteína no corpo vazio

Table 2 - Estimated daily increase in protein content of carcass and its components $(\mathrm{kg})$ in crossbred steers under continuous growth (GCont), and, or compensatory growth (GComp), by kg of protein gain in empty body

\begin{tabular}{|c|c|c|c|c|c|c|c|}
\hline \multirow[t]{2}{*}{$\begin{array}{l}\text { Componente } \\
\text { Component }\end{array}$} & \multicolumn{7}{|c|}{$\begin{array}{l}\text { Peso vivo }(\mathrm{kg}) \\
\text { Body weight }\end{array}$} \\
\hline & 150 & 200 & 250 & 300 & 350 & 400 & 450 \\
\hline & \multicolumn{7}{|c|}{ - } \\
\hline \multicolumn{8}{|l|}{$\begin{array}{l}\text { Carcaça } \\
\text { Carcass }\end{array}$} \\
\hline GCont & 0,5638 & 0,5649 & 0,5657 & 0,5664 & 0,5669 & 0,5674 & 0,5678 \\
\hline GComp & 0,5847 & 0,5858 & 0,5867 & 0,5874 & 0,5879 & 0,5884 & 0,5888 \\
\hline \multicolumn{8}{|l|}{$\begin{array}{l}\text { Músculo } \\
\text { Muscle }\end{array}$} \\
\hline GConte GComp & 0,4007 & 0,4226 & 0,4396 & 0,4537 & 0,4658 & 0,4763 & 0,4858 \\
\hline \multicolumn{8}{|l|}{$\begin{array}{l}\text { Tecido adiposo } \\
\text { Adipose tissue }\end{array}$} \\
\hline GCont & 0,0505 & 0,0554 & 0,0593 & 0,0626 & 0,0655 & 0,0681 & 0,0705 \\
\hline GComp & $-0,0427$ & $-0,0277$ & $-0,0200$ & $-0,0155$ & $-0,0125$ & $-0,0104$ & $-0,0088$ \\
\hline \multirow{2}{*}{\multicolumn{8}{|c|}{$\begin{array}{l}\text { Osso } \\
\text { Bone }\end{array}$}} \\
\hline & & & & & & & \\
\hline GCont & 0,1191 & 0,1146 & 0,1114 & 0,1089 & 0,1068 & 0,1051 & 0,1036 \\
\hline Gcomp & 0,1387 & 0,1334 & 0,1296 & 0,1267 & 0,1243 & 0,1223 & 0,1206 \\
\hline
\end{tabular}

( $b=1,16656751)$ e no tecido adiposo dos animais em ganho contínuo $(\mathrm{b}=1,288848)$ que no corpo, porém, as taxas de deposição de proteína nos ossos dos animais dos dois tratamentos foram menores $(b=0,87902)$ que o aumento de proteína no PCVZ. GUIMARÃES (1999) encontrou valor do coeficiente $\mathrm{b}=1,050337$, para aumento do peso da carcaça em relação ao PCVZ, para os tratamentos ganho contínuo e ganho compensatório.

Para os animais em ganho compensatório, pode-se verificar que, para cada $\mathrm{kg}$ de acréscimo de proteína no corpo vazio, houve redução de até $42,79 \mathrm{~g}$ de proteína no tecido adiposo, em animais com $150 \mathrm{~kg}$ de $\mathrm{PV}$, podendo-se admitir ausência de ganho líquido de proteína neste tecido. Este fato pode indicar ausência de hiperplasia/diferenciação de pré-adipócitos no tecido adiposo de animais em ganho compensatório. Por outro lado, o ganho de proteína no tecido adiposo de animais em ganho contínuo sugere a ocorrência de multiplicação ou diferenciação de pré-adipócitos nesses animais, o que evidencia que mais energia foi direcionada para o desenvolvimento do tecido adiposo. Deve-se salientar que os animais em ganho compensatório apresentaram ganho ligeiramente mais elevado de proteína na carcaça.

A restrição no consumo de nutrientes, particular- mente de proteína, pode reduzir o tamanho corporal à maturidade, aumentar o conteúdo de gordura na carcaça e reduzir a eficiência alimentar. No entanto, em estudos com alimentação forçada, não se verificou aumento na deposição de proteína corporal. Ao contrário, os nutrientes em excesso foram convertidos em lipídeos, excretados ou catabolizados, indicando que outros fatores, além do suprimento de nutrientes, podem inibir a deposição de proteína no corpo do animal (OWENS et al., 1993).

Os valores estimados de deposição de proteína na carcaça, para animais na faixa de 150 a $450 \mathrm{~kg}$ de peso vivo, por kg de proteína depositada no PCVZ (PrPCVZ), permaneceram próximos a 0,5661 e $0,5871 \mathrm{~kg} / \mathrm{kg}$ PrPCVZ, para os tratamentos ganho contínuo e ganho compensatório, respectivamente, e o valor médio para deposição de proteína no tecido muscular, para animais na mesma faixa de peso, foi de $0,4492 \mathrm{~kg} / \mathrm{kg}$ PrPCVZ. No entanto, a deposição de proteína no tecido adiposo variou de $0,0505 \mathrm{~g}$ a $0,0705 \mathrm{~kg} / \mathrm{kg}$ PrPCVZ, para o tratamento ganho contínuo, e de -0,0427 a -0,0088 kg/kg PrPCVZ, para o ganho compensatório, para animais pesando de 150 a $450 \mathrm{~kg}$ de PV.

O AGRICULTURAL AND FOOD RESEARCH COUNCIL - AFRC (1993) sumarizou padrões de 
alterações no peso e nos constituintes corporais de tipos raciais bovinos $(\mathrm{C})$ para raças pequenas, médias ou grandes, de acordo com o sexo, para predizer o valor energético (VE), em $\mathrm{MJ} / \mathrm{kg}$, e protéico (VP), em $\mathrm{g} /$ dia, da diferença no ganho diário de peso vivo (dPV), em kg, nas seguintes equações:

$\mathrm{VE}=\mathrm{C}\left(4,1+0,0332 \mathrm{PV}-0,000009 \mathrm{PV}^{2}\right) /$ $(1-0,1475 \mathrm{dPV})$ e $\mathrm{VP}=\mathrm{C}(168,07-0,16869 \mathrm{PV}+$ $\left.0,0001633 \mathrm{PV}^{2}\right)(1,12-0,1223 \mathrm{dPV})(1,695 \mathrm{dPV})$

Essas equações indicam que, para um animal a um determinado peso, o conteúdo de energia do peso ganho aumenta e o conteúdo protéico reduz com o aumento na taxa de ganho de peso.

As equações de regressão dos logaritmos dos conteúdos de gordura na carcaça e em seus componentes, em relação aos logaritmos dos conteúdos de gordura no corpo vazio, ao longo do período de confinamento, para animais com ganho de peso contínuo ou compensatório, estão relacionadas na Tabela 3 .

Houve diferença significativa na velocidade de deposição de gordura nos ossos da carcaça entre animais em ganho de peso contínuo $(b=0,26693229)$ e animais em ganho compensatório ( $b=0,57418327)$, porém, não foram detectadas diferenças para os demais componentes corporais, sendo a taxa de deposição de gordura na carcaça $(b=1,02511715)$ semelhante à de aumento de deposição de gordura no corpo vazio como um todo, enquanto no tecido muscular da carcaça a deposição de gordura situou-se abaixo da deposição no corpo vazio $(b=0,8548775)$ e no tecido adiposo da carcaça ocorreu em taxa mais rápida que a média do corpo vazio $(b=1,40284)$.

Os aumentos do conteúdo de gordura na carcaça e seus componentes foram estimados por meio das equações de predição e estão relacionados na Tabela 4.

Não houve diferença entre os tratamentos, quanto à velocidade de deposição de gordura na carcaça, nos músculos e no tecido adiposo da carcaça. Entretanto, a taxa de deposição de gordura nos ossos foi maior em animais em ganho compensatório. O valor estimado de deposição de gordura na carcaça para um animal de $300 \mathrm{~kg}$ de PCVZ, para os dois tratamentos, foi de $68,84 \mathrm{~g} / \mathrm{kg}$ GoPCVZ, sendo de 8,04 g/kg GoPCVZ para o tecido muscular e de 52,99 para o tecido adiposo, enquanto para o tecido ósseo foi de 2,93 e $9,90 \mathrm{~g} / \mathrm{kg}$ GoPCVZ, para os tratamentos ganho contínuo e ganho compensatório, respectivamente.

As equações de regressão dos logaritmos dos conteúdos de energia na carcaça e em seus componentes, em relação aos logaritmos dos conteúdos de energia no corpo vazio, ao longo do período de

Tabela 3 - Equações alométricas relacionando os conteúdos de gordura na carcaça e em seus componentes com o conteúdo no PCVZ e equações de predição do ganho de gordura na carcaça e em seus componentes, em função do ganho de $1 \mathrm{~kg}$ de gordura no corpo vazio (GoPCVZ), em novilhos mestiços em ganho contínuo (GCont) e, ou, ganho compensatório (GComp)

Table 3 - Allometric equations expressing the relation of fat contents of carcass and its components with fat content on EBW, and prediction equations of fat gain in carcass and its components, per $\mathrm{kg}$ of gain of fat in the empty body (GoPCVZ), in crossbred steers under continuous growth (GCont), and, or compensatory growth (GComp)

\begin{tabular}{|c|c|c|}
\hline Componente & Equações alométricas & Equações de predição \\
\hline Component & Allometric equations & Prediction equations \\
\hline
\end{tabular}

Carcaça

Carcass

\begin{tabular}{|c|c|c|c|}
\hline $\begin{array}{l}\text { GCont e GComp } \\
\text { Músculo } \\
\text { Muscle }\end{array}$ & $\hat{Y}=0,62251048 \times$ GoPCVZ $^{1,02511715}$ & $\hat{Y}=0,63814617 \times$ GoPCVZ $^{0,025117}$ & 0,97 \\
\hline $\begin{array}{l}\text { GCont e GComp } \\
\text { Tecido adiposo } \\
\text { Adipose tissue }\end{array}$ & $\hat{\mathrm{Y}}=0,14572373 \times \mathrm{GoPCVZ}^{0,85487751}$ & $\hat{\mathrm{Y}}=0,12457594 \times \mathrm{GoPCVZ}^{-0,145122}$ & 0,78 \\
\hline $\begin{array}{l}\text { GCont e GComp } \\
\text { Osso } \\
\text { Bone }\end{array}$ & $\hat{\mathrm{Y}}=0,1120530 \times \mathrm{GoPCVZ}^{1,40284121}$ & $\hat{\mathrm{Y}}=0,15719312 \times$ GoPCVZ $^{0,402841}$ & 0,94 \\
\hline $\begin{array}{l}\text { GCont } \\
\text { Gcomp }\end{array}$ & $\begin{array}{l}\hat{Y}=1,003531 \times \text { GoPCVZ }^{0,26693229} \\
\hat{Y}=0,622926 \times \text { GoPCVZ }^{0,57418327}\end{array}$ & $\begin{array}{l}\hat{Y}=0,26787480 \times \text { GoPCVZ }^{-0,733068} \\
\hat{Y}=0,35767341 \times \text { GoPCVZ }^{-0,425817}\end{array}$ & 0,73 \\
\hline
\end{tabular}


532 Rev. bras. zootec.

confinamento, para animais que experimentaram ganho de peso contínuo ou compensatório, estão relacionadas na Tabela 5 e o aumento do conteúdo de energia na carcaça e em seus componentes, estimados por meio das equações de predição, na Tabela 6 .
A taxa de acúmulo de energia na carcaça e em seus componentes acompanhou as alterações no conteúdo de gordura corporal. A deposição de energia na carcaça ocorreu em taxa semelhante à média do PCVZ ( $b=1,06015908)$, enquanto foi mais

Tabela 4 - Aumento diário estimado de gordura na carcaça e em seus componentes $(\mathrm{kg})$ de novilhos mestiços em ganho contínuo (GCont) e, ou, ganho compensatório (GComp), por kg de ganho de gordura no corpo vazio

Table 4 - Estimated daily increase in fat content in carcass and its components ( $\mathrm{kg}$ ) in crossbred steers under continuous growth (GCont), and, or compensatory growth (GComp), by $\mathrm{kg}$ of protein gain in empty body

\begin{tabular}{|c|c|c|c|c|c|c|c|}
\hline \multirow[t]{2}{*}{$\begin{array}{l}\text { Componente } \\
\text { Component }\end{array}$} & \multicolumn{7}{|c|}{$\begin{array}{l}\text { Peso vivo }(\mathrm{kg}) \\
\text { Bodyweight }\end{array}$} \\
\hline & 150 & 200 & 250 & 300 & 350 & 400 & 450 \\
\hline \multirow{2}{*}{\multicolumn{8}{|c|}{ 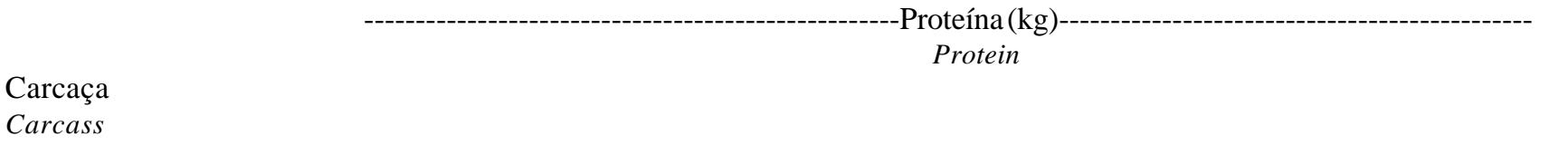 }} \\
\hline & & & & & & & \\
\hline \multicolumn{8}{|l|}{$\begin{array}{l}\text { Músculo } \\
\text { Muscle }\end{array}$} \\
\hline GCont e GComp & 0,1123 & 0,0974 & 0,0875 & 0,0804 & 0,0749 & 0,0705 & 0,0669 \\
\hline $\begin{array}{l}\text { Tecido adiposo } \\
\text { Adipose tissue }\end{array}$ & & & & & & & \\
\hline GCont e GComp & 0,2095 & 0,3115 & 0,4187 & 0,5299 & 0,6445 & 0,7622 & 0,8825 \\
\hline \multicolumn{8}{|l|}{ Osso } \\
\hline \multicolumn{8}{|l|}{ Bone } \\
\hline GCont & 0,1588 & 0,0772 & 0,0451 & 0,0293 & 0,0206 & 0,0151 & 0,0116 \\
\hline GComp & 0,2640 & 0,1736 & 0,1270 & 0,0990 & 0,0805 & 0,0674 & 0,0577 \\
\hline
\end{tabular}

Tabela 5 - Equações alométricas relacionando o conteúdo de energia na carcaça e em seus componentes com o conteúdo no PCVZ e equações de predição do ganho de energia na carcaça e em seus componentes, em função do ganho de 1 Mcal de energia no corpo vazio (EnPCVZ), em novilhos mestiços em ganho contínuo (GCont) e, ou, ganho compensatório (GComp)

Table 5 - Allometric equations expressing the relation of energy content in carcass and its components with energy content of EBW, and prediction equations of fat gain in carcass and its components per Mcal of gain of energy in the empty body (EnPCVZ), in crossbred steers under continuous growth (GCont), and, or compensatory growth (GComp)

\begin{tabular}{|c|c|c|c|}
\hline $\begin{array}{l}\text { Componente } \\
\text { Component }\end{array}$ & $\begin{array}{l}\text { Equações alométricas } \\
\text { Allometric equations }\end{array}$ & $\begin{array}{l}\text { Equações de predição } \\
\text { Prediction equations }\end{array}$ & $\mathrm{R}^{2}$ \\
\hline \multicolumn{4}{|c|}{$\begin{array}{c}\text { Energy } \\
\text { Englal }\end{array}$} \\
\hline \multicolumn{4}{|l|}{$\begin{array}{l}\text { Carcaça } \\
\text { Carcass }\end{array}$} \\
\hline $\begin{array}{l}\text { GCont e Gcomp } \\
\text { Músculo } \\
\text { Muscle }\end{array}$ & $\hat{Y}=0,422800755 \times E^{2 n P C V Z}{ }^{1,060159}$ & $\hat{\mathrm{Y}}=0,44823606 \times \mathrm{EnPCVZ}^{0,060159}$ & 0,99 \\
\hline $\begin{array}{l}\text { GCont e Gcomp } \\
\text { Tecido adiposo } \\
\text { Adipose tissue }\end{array}$ & $\hat{Y}=1,27896748 \times \operatorname{EnPCVZ}^{0,748399}$ & $\hat{\mathrm{Y}}=0,95717741 \times \mathrm{EnPCVZ}^{-0,251601}$ & 0,96 \\
\hline $\begin{array}{l}\text { GCont e GComp } \\
\text { Osso } \\
\text { Bone }\end{array}$ & $\hat{Y}=0,00049385 \times E_{E n P C Z}^{1,95178479}$ & $\hat{Y}=0,00096389 \times E^{2 n P C V Z}{ }^{0,951785}$ & 0,92 \\
\hline $\begin{array}{l}\text { GCont } \\
\text { Gcomp }\end{array}$ & $\begin{array}{l}\hat{Y}=1,52806 \times \operatorname{EnPCVZ}^{0,58385932} \\
\hat{Y}=2,00311 \times \operatorname{EnPCVZ}^{0,58385932}\end{array}$ & $\begin{array}{l}\hat{\mathrm{Y}}=0,89217179 \times \operatorname{EnPCVZ}^{-0,416141} \\
\hat{\mathrm{Y}}=1,16953735 \times \text { EnPCVZ }^{-0,416141}\end{array}$ & 0,84 \\
\hline
\end{tabular}


ALMEIDA et al.

Tabela 6 - Aumento diário de energia estimado na carcaça e seus componentes (kcal) de novilhos mestiços em ganho contínuo (GCont) e, ou, ganho compensatório (GComp), por Mcal de ganho de energia no corpo vazio

Table 6 - Estimated daily increase in energy content of carcass and its components in crossbred steers in continuous growth (GCont), and, or compensatory growth (GComp), by Mcal of energy gain in empty body

\begin{tabular}{|c|c|c|c|c|c|c|c|}
\hline \multirow[t]{2}{*}{$\begin{array}{l}\text { Componente } \\
\text { Component }\end{array}$} & \multicolumn{7}{|c|}{$\begin{array}{l}\text { Peso vivo }(\mathrm{kg}) \\
\text { Bodyweight }\end{array}$} \\
\hline & 150 & 200 & 250 & 300 & 350 & 400 & 450 \\
\hline & \multicolumn{7}{|c|}{ 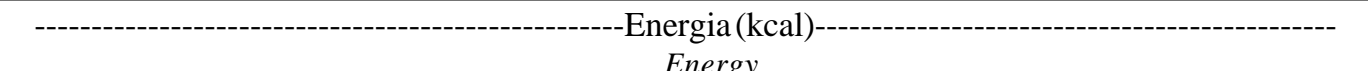 } \\
\hline $\begin{array}{l}\text { Carcaça } \\
\text { Carcass }\end{array}$ & & & & & & & \\
\hline $\begin{array}{l}\text { GConte GComp } \\
\text { Músculo } \\
\text { Muscle }\end{array}$ & 600,40 & 625,93 & 641,37 & 652,56 & 661,38 & 668,67 & 674,90 \\
\hline $\begin{array}{l}\text { GCont e GComp } \\
\text { Tecido Adiposo } \\
\text { Adipose tissue }\end{array}$ & 281,93 & 236,86 & 213,90 & 198,98 & 188,12 & 179,68 & 172,85 \\
\hline $\begin{array}{l}\text { GCont e GComp } \\
\text { Osso } \\
\text { Bone }\end{array}$ & 98,22 & 189,83 & 279,15 & 367,03 & 453,84 & 539,81 & 625,09 \\
\hline GCont & 118,15 & 88,58 & 74,83 & 66,39 & 60,51 & 56,09 & 52,60 \\
\hline GComp & 154,88 & 116,11 & 98,10 & 87,03 & 79,32 & 73,53 & 68,96 \\
\hline
\end{tabular}

elevada no tecido adiposo $(b=1,95178479)$ e mais baixa nos tecidos muscular $(b=0,748399)$ e ósseo $(\mathrm{b}=0,58385932)$. À medida que o peso dos animais se elevou de 150 para $450 \mathrm{~kg}$, verificou-se aumento da proporção de energia depositada na carcaça, tendo os valores se elevado de $600,4 \mathrm{kcal} / \mathrm{Mcal}$, em animais de $150 \mathrm{~kg}$, para $674,0 \mathrm{kcal} / \mathrm{Mcal}$, em animais de $450 \mathrm{~kg}$ de PV.

A deposição de energia no tecido muscular reduziu de 281,93 kcal/Mcal, em animais de $150 \mathrm{~kg}$, para $172,85 \mathrm{kcal} / \mathrm{Mcal}$, em animais de $450 \mathrm{~kg}$ de PV, enquanto a deposição de energia no tecido adiposo se elevou de 98,22 kcal/Mcal EnPCVZ para 625,09 $\mathrm{kcal} / \mathrm{Mcal}$ EnPCVZ, quando os animais passaram de 150 para $450 \mathrm{~kg}$ de PV. Por outro lado, a deposição média de energia no tecido ósseo foi de 73,88 kcal/ Mcal EnPCVZ, para os animais em ganho contínuo, e de $96,85 \mathrm{kcal} / \mathrm{Mcal}$ EnPCVZ, para aqueles em ganho compensatório.

Segundo HORNICK et al. (1998), o maior crescimento muscular muitas vezes observado nos bovinos submetidos a ganho compensatório pode ser justificado pelo estímulo do eixo somatotrópico, aumentando a concentração plasmática de hormônios anabólicos, como a insulina, o IGF-1 e os hormônios tireoideanos, principalmente o $\mathrm{T}_{3}$. Estas alterações ocorrem no início do ganho com- pensatório, quando os animais são alimentados $a d$ libitum, e após determinado período de realimentação ocorre maior deposição de tecido adiposo na carcaça, em função do aumento acentuado da concentração plasmática da insulina em relação ao hormônio de crescimento.

\section{Conclusões}

A restrição alimentar no período que antecedeu ao confinamento não influenciou as deposições de proteína, gordura e energia na carcaça.

A deposição de proteína no tecido muscular ocorreu em taxa superior à do PCVZ, enquanto as deposições de gordura e energia nos músculos da carcaça ocorreram em taxas mais baixas que no corpo vazio. O ganho de peso compensatório reduziu a taxa de deposição de proteína no tecido adiposo da carcaça. A deposição de proteína nos ossos da carcaça ocorreu em taxa inferior à do corpo vazio.

A taxa de deposição de gordura foi maior nos ossos da carcaça dos animais em ganho compensatório do que nos animais em ganho contínuo. Nos demais componentes da carcaça, não foram detectadas diferenças na taxa de deposição de gordura, em virtude do efeito do ganho compensatório. 


\section{Referências Bibliográficas}

AGRICULTURAL AND FOOD RESEARCH COUNCIL AFRC. 1993. Energy and protein requirements of ruminants. Wallingford, UK: CAB International. 159p.

ALMEIDA, M.I.V., FONTES, C.A.A., ALMEIDA, F.Q. et al. 2001. Conteúdo corporal e exigências líquidas de energia e proteína de novilhos mestiços holandês-gir em ganho compensatório. Rev. bras. zootec., 30(1):205-214.

BERG, R.T., BUTTERFIELD, R.M. 1976. New concepts of cattle growth. Sydney: Sydney Univerty Press. 240p.

FRANCI, O., ACCIAIOLI, A., BOZZI, R. et al. 1996. Growth patterns of Chianina bull from 6 to 24 months fed two different diets. 2. Tissues. Livest. Prod. Sci., 46:191-201.

GIORGETTI, A., FRANCI, O., MARTINI, A. et al. 1996. Growth patterns of Chianina bull from 6 to 24 months fed two different diets. 1. Organs and carcass. Livest. Prod. Sci., 46:181-190.

GRANT, A.L., HELFERICH, W.G. 1991. An overview of growth. In: PEARSON, A.M., DUTSON, T.R. (Eds.) Growth regulation in farm animals. Advances in meat research. London and New York: Elsevier Applied Science. v.7, p.1-16.

GRAYBILL, F.A. 1976. Theory and application of the linear model. Massachussetts: Duxburg Press. 704p.

GUIMARÃES, R.F. Ganho de peso, consumo e conversão alimentar, composição corporal e características de carcaça de novilhos mestiços durante o ganho compensatório. Viçosa, MG: UFV, 1999. 111p. Dissertação (Mestrado em Zootecnia) - Universidade Federal de Viçosa, 1999.

HANKINS, O.G., HOWE, P.E. 1946. Estimation of the composition of beef carcasses and cuts. s.e., USDA, (Technical Bulletin, 926).

HARVEY, W.R. 1987. Mixed model least squares and maximum likelihood computer program (LSMLWM) Versão PC - 1.59p.
HORNICK, J.L., VAN EENAEME, C., DIEZ, M. et al. 1998 Different periods of feed restriction before compensatory growth in Belgian Blue bulls: II. Plasma metabolites and hormones. J. Anim. Sci., 76: 260-271.

INSTITUT NATIONAL DE LA RECHERCHE AGRONOMIQUE - INRA. 1989. Ruminant nutrition: recommended allowances and feed tables. Libbey Eurotext, Paris. 389p.

KOCK, S.W., PRESTON, R.L. 1979. Estimation of bovine carcass composition by the urea dilution technique. J. Anim. Sci., 48(2): 319-327.

NATIONAL RESEARCH COUNCIL - NRC. 1996. Nutrient requirements of beef cattle. 7.ed. Washington, D.C. 242p.

NETER, J. WASSERMAN, W. 1974. Applied linear statistical models. Illinois: Richard D. Irwim, Homewood. 842p.

OLTJEN, J.W., BYWATER, R.L., BALDWIN, R.L. et al. 1986. Development of a dynamic model of beef cattle growth and composition. J. Anim. Sci., 62:86-97.

OWENS, F.N., DUBESKI, P., HANSON, C.F. 1993. Factors that alter the growth and development of ruminants. J. Anim. Sci., 71:3138-3150.

SEEBECK, S.M. 1968. Developmental studies of body composition. Anim. Breed. Abstr., 36:167-181.

Recebido em: 18/07/00

Aceito em: 19/11/00 